\title{
Analisis P/B Rasio Foraminifera di Perairan Delta Wulan, Demak, Jawa Tengah
}

\author{
Bifa Aulia Manuhuwa*, Retno Hartati, Hadi Endrawati \\ Departemen IImu Kelautan, Fakultas Perikanan dan IImu Kelautan, Universitas Diponegoro \\ JI. Prof.H.Soedarto S.H, Tembalang, Semarang, Jawa Tengah 50275 Indonesia \\ ${ }^{*}$ Corresponding author, e-mail : bifamanuhuwa@hotmail.com
}

\begin{abstract}
ABSTRAK: Foraminifera merupakan organisme uniseluler yang dapat berperan sebagai indikator lingkungan serta dapat menentukan lingkungan pengendapan. Foraminifera banyak hidup di perairan laut dalam maupun dangkal seperti di perairan Delta Wulan, Demak. Litologi penyusun Delta Wulan ini berupa endapan sedimen berumur kuarter. Tujuan dari penelitian ini adalah untuk menganalisa komposisi foraminifera planktonic dan bentik serta $\mathrm{P} / \mathrm{b}$ rasio sebagai indikator lingkungan pengendapan. Metode survey eksploratif digunakan dalam penelitian ini. Pengambilan sampel dilakukan secara purposive sampling di 12 titik penelitian. Penelitian ini berhasil menemukan 24 genus foraminifera yang termasuk 4 kelas, yaitu Globothalamea, Fusulinata, Tubothalamea dan Nodosariata. Terdapat lebih banyak genus foraminifera bentik (17 genus) daripada planktonik (7 genus) yang termasuk ke dalam 7 Ordo yaitu Rotaliida, Textulariida, Loftusiida, Earlandiida, Miliolida, Vaginulinida, dan Lituolida. Nilai P/B rasio berkisar antara 8693\% yang menunjukkan bahwa jumlah individu foraminifera planktonik lebih banyak daripada bentonik dan rasio tersebut menunjukkan kategori batimetri batial atas.
\end{abstract}

Kata kunci : bentonik; foraminifera; planktonic; paleoenvrionment.

\section{Analyzes of P/B Ratio of Foraminifera In Delta Wulan Watres, Demak, Central of Java}

ABSTRACT: Foraminifera is an unicellular organism that can act as an environmental indicator and can determine the depositional environment. The way of life of foraminifera is divided into two namely planktonic foraminifera (floating) and bentonic foraminifera (tethering). The role of foraminifera as an ideal indicator organism because it has a relatively short life cycle thus facilitating episodic recording events. At present many foraminifera live in shallow and deep sea waters such as the Wulan Delta, Demak. This Wulan Delta lithology is still in the form of sediment deposits which can be seen that this delta is Quaternary age. Thus, the percentage $P / b$ ratio can be used to analyze the depositional environment. The purpose of this research is to determine the composition of foraminifera and $P / b$ ratio as indicators of depositional environment. Samples were taken from 12 sampling point. This study reveal to identify 24 genera of foraminifera which belong to 4 classes, namely Globothalamea, Fusulinata, Tubothalamea and Nodosariata. There are more benthic foraminifera (17 genera) than planktonic (7 genera) which belong to 7 orders namely Rotaliida, Textulariida, Loftusiida, Earlandiida, Miliolida, Vaginulinida, and Lituolida. The $P$ / $B$ ratio values ranged from $86-93 \%$ which indicated that the number of planktonic foraminifera individuals was more than bentonic and this ratio indicated the upper batial bathymetry category.

Keywords : benthonic; foraminifera; planktonic; paleoenvrionment

\section{PENDAHULUAN}

Foraminifera merupakan kelompok organisme bercangkang yang tergolong ke dalam Subfilum Sarcodina, filum Protozoa, dan keberadaannya melimpah di berbagai lingkungan laut (Organisme ini memiliki ukuran tubuh 0.1-2 mm (Levinton, 2009), dapat hidup secara melayang (planktonik) maupun di dasar laut (bentonik), memiliki satu atau lebih kamar yang terpisah satu sama lain oleh sekat (septa) yang ditembus oleh banyak lubang halus (foramen) (Jurnaliah et al, 2017). Foraminifera berperan sebagai organisme indikator yang ideal karena memiliki siklus hidup relatif singkat sehingga memfasilitasi peristiwa rekaman episodik, ukuran yang relatif kecil dan 
jumlahnya yang melimpah, proses pengkoleksiannya tidak berdampak terhadap sumberdaya alam, dan tidak mengganggu keseimbangan ekosistem lingkungan laut (Hallock et al., 2003). Organisme ini banyak hidup di perairan laut dalam dan dangkal seperti di Delta Wulan, Demak.

Delta Wulan merupakan daerah pesisir pantai utara Jawa Tengah seluas area $25 \mathrm{~km}^{2}$ (Atmojo et al., 2016). Delta Wulan mengalami perkembangan ke arah laut dari waktu ke waktu karena dipengaruh aktivitas pasang surut. Perkembangan tersebut dapat dilihat dengan adanya percabangan di bagian muara Sungai Wulan, sehingga muara sungai tersebut terbagi menjadi dua, yaitu muara lama dan muara baru. Masing-masing muara menerima transfer sedimen yang berasal dari hulu dan mengendap di perairan Delta Wulan, Demak. Sedimen yang terangkut dapat mengendap dengan mudah karena aktivitas pasang surut dan arus laut di daerah tersebut (Atmojo et al., 2016).

Data distribusi dan kelimpahan foraminfera dapat digunakan sebagai proksi paleoenvironment. Banyak dari data tersebut menghasilkan informasi kualitatif dan kuantitatif untuk menentukan batimetri, kedalaman air atau perubahan muka laut relatif (Leckie dan Olson, 2003). Informasi kuantitatif terutama tentang jumlah individu dari genus atau spesies dari foraminifera dapat digunakan untuk berbagai tujuan (Murray dan Rohling, 2012), antara lain untuk . merekonstruksi lingkungan purba (Van Marle, 1989). Menurut Jurnaliah et al. (2017) dalam metode kuantitatif, rasio $\mathrm{P} / \mathrm{B}$ atau perbandingan foraminifera plantonik dan bentik dapat digunakan dalam penentuan lingkungan laut dangkal dan laut dalam serta untuk mengetahui kedalaman dan paleoenvironment suatu daerah. Analisa Rasio $\mathrm{P} / \mathrm{b}$ pada foraminifera ini pernah dilakukan di perairan sekitar Pulau Derawan, Kalimantan Timur Gustiantini et al., 2005), pada Formasi Kalibeng pada Kala Miosen Tengah di Jawa Tengah (Jurnaliah et al., 2016) dan di perairan Selat Benggala dan sekitarnya di Aceh (Natsir dan Wibowo, 2019). Sehingga dalam penelitian ini bertujuan unutk mengetahui jenis foraminifera planktonik dan bentonik dan rasio keduanya (P/b Rasio) serta untuk mengetahui kedalaman dan paleoenvironment perairan Delta Wulan, Demak,

\section{MATERI DAN METODE}

Materi yang digunakan adalah foraminifera dan sedimen dasar yang diambil di perairan Delta Wulan, Demak. Pada saat pengambilan sample foraminifera dan sedimen, juga dilakukan pengukuran suhu air, kecerahan, $\mathrm{pH}$, salinitas dan oksigen terlarut. Variabel yang diukur pada penelitian ini adalah ukuran butir sedimen, bahan organik total dan identifikasi serta enumerasi foraminifera.

Sampel sedimen yang berisi foraminifera diambil menggunakan grab sampler dengan luas bukaan 0,035 $\mathrm{m}^{2}$ dan disimpan di dalam plastik. Di Laboratorium Biologi Kelautan, FPIK, Undip, sampel sedimen yang berisi I foraminifera kemudian dicuci dengan air bersih sebanyak $2-3$ kali, kemudian dikeringkan dengan cara dijemur. Setelah dikeringkan sampel dihaluskan dengan menggunakan mangkuk porselen, kemudian diayak menggunakan mesh 0,063 mm, 0,125 mm dan $0,250 \mathrm{~mm}$. Sampel yang telah diayak dimasukan ke dalam plastic sampel dan diberi kode sesuai nomor sampel. Kemudian sample foraminifera dipisahkan dengan metode picking di bawah mikroskop binokuler dan dipisahkan berdasarkan foraminifera planktonik dan bentonik terhadap 300 individu foraminifera. Dalam penggunaan metode rasio P/B tidak diperlukan nama genus (spesies) dari setiap foraminifera yang ditemukan, akan tetapi hanya dibedakan (mengidentifikasi) jenis foraminifera planktonik dan bentonik berdasarkan morfologi cangkangnya (Jurnaliah et al. 2017) diantaranya bentuk cangkang, bentuk kamar, formasi kamar, jumlah kamar, ornamentasi cangkang, kemiringan apertura, posisi aperture dan kamar tambahan (Natsir dan Wibowo, 2019) dan diidentifikasi berdasarkan Postuma (1971); Morkhoven et al. (1986); serta Loeblich dan Tappan (1994).

Jumlah individu foraminifera planktonik dan foraminifera bentonik kemudian digunakan untuk mengetahui kedalaman dan paleoenvironment dengan menggunakan rumus $\mathrm{P} / \mathrm{b}$ Rasio menurut Van Marle (1989). Nilai $\mathrm{P} / \mathrm{b}$ rasio kemudian digunakan untuk mengetahui paleoenvironment di Delta Wulan berdasarkan Grimsdale dan Van Morkhovern (1955) (Tabel 1). 
Tabel 1. Paleoenvironment dan klasifikasi P/b Rasio berdasarkan Grimsdale dan Morkhovern (1955)

\begin{tabular}{lll}
\hline No & $\mathrm{P} / \mathrm{b}(\%)$ & Lingkungan \\
\hline 1 & $<20$ & Neritik Dalam \\
2 & $20-60$ & Neritik Tengah \\
3 & $40-70$ & Neritik Luar \\
4 & $>70$ & Batial Atas \\
5 & $>95$ & Batial Bawah \\
\hline
\end{tabular}

\section{HASIL DAN PEMBAHASAN}

Hasil identifikasi dari bentuk cangkangnya, terdapat 24 genus foraminifera di perairan Delta Wulan yang termasuk ke dalam 7 Ordo (Rotaliida, Textulariida, Loftusiida, Earlandiida, Miliolida, Vaginulinida, dan Lituolida) dan 4 kelas (Globothalamea, Fusulinata, Tubothalamea dan Nodosariata), yang terdiri dari 7 genus foraminifera planktonik dan 17 genus foraminifera bentonik. Foraminifera planktonik mempunyai pola hidup melayang dalam kolom air sangat dipengaruhi oleh pola arus yang terdapat di perairan tersebut, sedangkan foraminifera bentik mempunyai pola hidup di sekitar dasar suatu perairan dan ditemukan lebih banyak genusnya dibandingan dengan yang planktonik. Namun jumlah individu foraminifera planktonik ditemukan lebih melimpah dibandingan dengan yang bentik sehingga P/b Rasionya di perairan Delta Wulan, Demak berkisar 88-93,3\% (Tabel 2).

Berdasarkan $\mathrm{P} / \mathrm{b}$ rasio, nampak bahwa foraminifera pada setiap titik sampling terdapat pada daerah bathial atas, namun sampel penelitian diambil pada daerah transisi hingga pantai, sehingga dapat diinterpretasikan bahwa foraminifera planktonik merupakan hasil transportasi dari laut. Arus laut yang cukup tinggi membawa foraminifera planktonik ke daerah transisi dan kemudian energinya berkurang, sehingga foraminifera tersebut dapat terendapkan di lokasi pengambilan sampel (Malawani et al., 2018; Natsir dan Wibowo, 2019).

Hasil penelitian Atmojo et al. (2016) menunjukkan stratigrafi sampel sedimen perairan Delta Wulan, Demak berumur Kuarter. Litologi dari perairan tersebut di dominasi oleh Lanau. Hasil penelitian menunjukan lingkungan pengendapan pada kala itu adalah lingkungan marine dengan di temukannya jumlah foraminifera planktonik yang lebih banyak.

Tabel 2. Perbandingan Foramanifera Planktonik dan Bentonik (P/b Rasio) yang ditemukan pada masing - masing Titik di Lokasi Penelitian Delta Wulan, Demak

\begin{tabular}{lccccc}
\hline \multirow{2}{*}{ Titik } & \multicolumn{2}{c}{ Jumlah foraminifera } & $\begin{array}{c}\text { Presentase } \\
(\%)\end{array}$ & $\begin{array}{c}\text { Kedalaman } \\
(\mathrm{m})\end{array}$ & $\begin{array}{c}\text { Bathimetri } \\
\text { (Grimsdale dan } \\
\text { Morkhoven, 1955) }\end{array}$ \\
\cline { 2 - 4 } Planktonik & Bentonik & 92,3 & $1200-2000$ & Bathial Atas \\
\hline DW1 & 277 & 23 & 90,7 & $1200-2000$ & Bathial Atas \\
DW2 & 272 & 28 & 93,3 & $1200-2000$ & Bathial Atas \\
DW3 & 280 & 20 & 90,3 & $1200-2000$ & Bathial Atas \\
DW4 & 271 & 29 & 86,7 & $900-1200$ & Bathial Atas \\
DW5 & 260 & 40 & 88,0 & $900-1200$ & Bathial Atas \\
DW6 & 264 & 36 & 90,3 & $1200-2000$ & Bathial Atas \\
DW7 & 271 & 29 & 89,3 & $900-1200$ & Bathial Atas \\
DW8 & 268 & 32 & 92,0 & $1200-2000$ & Bathial Atas \\
DW9 & 276 & 24 & 89,7 & $900-1200$ & Bathial Atas \\
DW10 & 269 & 31 & 88,7 & $900-1200$ & Bathial Atas \\
DW11 & 266 & 34 & & & Bathial Atas \\
DW12 & 269 & 31 & 89,7 & $900-1200$ & .
\end{tabular}


Terjadinya perubahan nilai $\mathrm{P} / \mathrm{b}$ Rasio pada setiap sampel menunjukan adanya perubahan lingkungan. Pada kala Kuarter, daerah penelitian secara umum merupakan daerah dengan lingkungan marin yang terdiri dari zona neritik dan oseanik (Lübbers et al., 2019). Perubahan lingkungan marin pada umur Kuarter dapat diduga karena adanya pengaruh oleh beberapa faktor diantaranya adalah perubahan muka air laut dan perubahan iklim. Namun, perlu dilakukan penelitian lebih lanjutuntuk mengetahui penyebab terjadinya perubahan lingkungan marin menjadi perairan dangkal seperti di daerah penelitian (Marfai et al., 2016).

Nilai rasio P/B foraminifera tergantung pada morfologi dasar laut dan pola arus. Pada stasiun penelitian yang berdekatan dengan lereng pada penelitian (Natsir dan Wibowo, 2019) terjadi percampuran foraminifera bentik penciri laut dangkal bercampur dengan foraminifera planktonik. Percampuran ini menghasilkan nilai rasio PB sedang walupun mempunyai kedalaman tinggi. Variasi nilai rasio PB di daerah penelitian hampir serupa dengan hasil penelitian Gustiantini et al., (2005) di sekitar Pulau Derawan Kalimantan Timur. Kedalaman bukan satu-satunya faktor yang mempengaruhi diversitas dan distribusi foraminifera (Natsir et al., 2017) namun ada parameter lain seperti pola arus dan gelombang serta faktor-faktor lain (Natsir dan Wibowo, 2019).

Penggunaan $\mathrm{P} / \mathrm{B}$ rasio untuk menentukan umur lingkungan pengendapan juga dilakukan oleh Jurnaliah et al. (2016) pada Lintasan Kali Jragung Formasi Kalibeng berdasarkan hasil rasio $\mathrm{P} / \mathrm{B}$. Hasil penelitian menunjukkan lingkungan pengendapan daerah penelitian selama Kala Miosen Akhir adalah lingkungan laut dalam (oseanik) dengan perubahan kedalaman dimulai dari zona batial atas kemudian mendalam menjadi zona batial bawah, selanjutnya mendangkal kembali menjadi zona batial atas. Hal lain ditunjukan oleh penelitian yang dilakukan oleh Jurnaliah et al., (2016; 2017), yaitu lingkungan pengendapan menggunakan metode $\mathrm{P} / \mathrm{b}$ rasio di Kabupaten Demak, nilai persentase $\mathrm{P} / \mathrm{b}$ Rasio yang didapatkan berkisar $60-95 \%$ dan pada penelitian tersebut dijelaskan bahwa pada Kawasan Kabupaten Demak merupakan daerah yang berumur miosen akhir dengan kondisi perairannya yaitu lingkungan laut.

Lokasi penelitian yang terletak di Delta Wulan, Desa Wedung, Kabupaten Demak tersusun atas endapan Aluvium berumur kuarter dengan material penyusun berupa kerikil, pasir, lempung, lanau, sisa tumbuhan dan batuan gunungapi. Delta wulan merupakan bagian daratan yang menjorok ke laut yang terbentuk akibat proses penumpukan sedimen atau sedimentasi berumur Kuarter di Desa Wedung, Demak (Atmojo et al, 2016; Malawani et al., 2018). Secara regional daerah penelitian tersusun atas beberapa formasi batuan dengan umur geologi Miosen hingga holosen. Berdasarkan Suwarti dan Wikarno (1992) formasi batuan geologi di daerah penelitian adalah Ngrayong (Tmn), Bulu (Tmb), Patiayam (Tpp), Gunungapi Genuk (vg), Tuff Muria (QQvtm), Lava Muria (Qvlm,) dan Aluvium (Qa). Berdasarkan analisis ukuran butir sedimen dasar perairan Delta Wulan termasuk dalam kategori lanau dengan persentase rata - rata pasir $10,71 \%$, lanau $83,18 \%$ dan lempung 6,09\%. Rerata suhu di perairan Delta Wulan $30,2^{\circ} \mathrm{C}$. Setiap jenis foraminifera beradaptasi pada kisaran suhu tertentu yaitu $4-32^{\circ} \mathrm{C}$. Titik kritis dari kisaran ini tercapai bila proses reproduksi sudah tidak dapat berlangsung (Rositasari dan Sudibjo, 2008). Batas kisaran ini akan semakin sempit pada jenis-jenis yang hidup di lingkungan beriklim tropis. Pelapisan air di samudra menyebabkan terjadinya penurunan suhu yang progresif pada lapisan air terdalam. sebagai contoh suhu permukaan air tropis berkisar antara $25-28^{\circ} \mathrm{C}$ padahal suhu paparan abisal dapat mencapai rata-rata $4^{\circ} \mathrm{C}$. Perairan dingin di kedalaman laut ini biasanya dihuni oleh kumpulan foraminfera bentonik yang telah beradaptasi terhadap lingkungan tersebut, namun dilain pihak jenis ini pun merupakan jenis endemik di perairan dangkal daerah-daerah di sub tropis (Rositasari, 1997). Kebanyakan foraminifera beradaptasi pada salinitas normal, sehingga pada lingkungan tersebut keanekaragaman jenis foraminifera biasanya tinggi. Lingkungan bersalinitas rendah seperti teluk berair payau dan rawa-rawa biasanya dihuni oleh foraminifera agglutinin dengan keanekaragaman rendah. Salinitas perairan Delta Wulan $25,4 \%$. Foraminifera yang beradaptasi pada salinitas rendah dicirikan dengan cangkang yang tersusun dari silikat atau berperekat unsur-unsur bersifat besi seperti famili Rheoplax dan famili Rotaliacea tertentu seperti Ammonia. Marga Allogromiina yang lunak dengan cangkang tektin ditemukan di perairan tawar dan payau. Konsentrasi kalsium karbonat yang tinggi pada perairan bersalinitas tinggi (Hyper-saline) disukai oleh jenis-jenis bercangkang seperti porselen (Porcellanous) seperti Miliolina (Rositasari, 1997). 


\section{KESIMPULAN}

Terdapat lebih banyak genus foraminifera bentik (17 genus) daripada planktonik ( 7 genus) yang termasuk ke dalam 7 Ordo yaitu Rotaliida, Textulariida, Loftusiida, Earlandiida, Miliolida, Vaginulinida, dan Lituolida. Nilai P/B rasio berkisar antara $86-93 \%$ yang menunjukkan bahwa jumlah individu foraminifera planktonik lebih banyak daripada bentonik dan rasio tersebut menunjukkan kategori batimetri batial atas.

\section{DAFTAR PUSTAKA}

Atmojo, H.T., Wicaksana, H.I., Rizal, A., Cibaj, I, Nugroho, H., \& Ralanarko, D. 2016. 3D Modelling of Longshore Bar Deposit in Modern Fluvial Dominated Delta: Case Study of Wulan Delta, Demak, Central Java Province. GEO 2016, 12th Middle East Geosciences Conference and Exhibition, Manama, Bahrain, March 7-10, 2016. Bahrain.

Grimsdale, T.F., \& Van Morkhoven F.P.C.M. 1955. The ratio between Pelagic and Benthonic Foraminifera as a means of estimating depth of deposition of sedimentary rocks. In Proceedings 4th World Petroleum Congress Rome, Italy.

Gustiantini, L., Dewi., K.T. \& Illahude, D., 2005. Perbandingan foraminifera bentik dan plangtonik (P/B ratio) diperairan sekitar Pulau Derawan, Kalimantan Timur. Proceedings of Joint Convention The 3OHAGI, 34 ${ }^{T H}$ IAGI and The 14 ${ }^{\text {th }}$ HPERHAPI Annual Converence and Exhibition, Surabaya: 341-348

Hallock, P., Lidz, B.H, \& Cockey-Burkhard, K.B..2003. Foraminifera as Bioindicators in Coral Reef Assessment and Monitoring: the FORAM Index. Environmental Monitoring and Assessment $81: 221-238$.

Jurnaliah, L., Winantris, \& Fauzielly, L. 2017. Metode kuantitatif foraminifera kecil dalam penentuan lingkungan. Bulletin of Scientific Contribution, 15(3): 211- 216

Jurnaliah, L., Muhamadsyah, F. \& Barkah, N. 2016. Lingkungan Pengendapan Formasi Kalibeng Pada Kala Miosen Akhir di Kabupaten Demak dan Kabupaten Semarang, Jawa Tengah Berdasarkan Rasio Foraminifera Plangtonik dan Bentonik (Rasio P/B). Bulletin of Scientific Contribution, 14(3):233-238.

Leckie, R.M. \& Olson, H.C. 2003. Foraminifera as Proxies For Sea-Level Change on Silisiclastic Margins. SEPM Special Publication 75:5-19.

Levinton, J.S. 2009. Marine Biology. Function, Biodiversity, Ecology. 3rd Edition. Stony Book Univ. Oxford Univ. Press. 588 p.

Loeblich, A.R. \& Tappan, H. 1994. Foraminifera of the Sahul Shelf And Timor Sea. Cushman Foundation for Foraminiferal Research, Special Publication No. 31.

Lübbers, J., Wfgang, K., Ann, H., Clara T.B., Emmeline, G., Usui, Y., Karlos, K., Diemer, G., Sebastian, B. \& Nils, A. 2019. The Middle to Late Miocene "Carbonate Crash" in the Equatorial Indian Ocean. Paleoceanography and Paleoclimatology, 34(5):813-832. Doi : 10.1029/2018 PA003482

Marfai, M.A., Tyas, D.W., Nugraha, I., Ulya, A.Y. \& Riasasi, W. 2016. The Morphodynamics of Wulan Delta and Its Impacts on the Coastal Community in Wedung Subdistrict, Demak Regency, Indonesia. Journal of Environmental Protection. 7:60-71.

Malawani, M.N., Sunarto, Handayani, T. \& Yoga, A.G.H. 2018. Recent delta evolution based on mollusk shell record on sediment in Delta Wulan, Demak, Indonesia. Geomedia 16(2):81-87

Morkhoven, F.P.C.M., Berggren, W.A., \& Edwards, A.S. 1986. Cenozoic Comopolitan Depp-water Benthic Foraminifera. Elf Aquitaine: France

Murray, J.W. 2006. Ecology \& Applications of Benthic Foraminifera. Cambridge University Press. UK; hal. 327-343. 
Natsir, N.S., Dewi, K.T. \& Ardyastuti, S., 2017. Keterkaitan Foraminifera dan kedalaman perairan sekitar Pulau Seram, Jurnal Geologi Kelautan 15(2): 73-79

Natsir, S.M., \& Wibowo, S.P.A. 2019. Diversitas dan distribusi foraminifera di Selat Benggala dan sekitarnya, Aceh. Jurnal Geologi Kelautan 17(1):1-8

Postuma, J.A. 1971. Manual Of Planktonik Foraminifera. Elsevier Publishing Company: Amsterdam, London, New York.

Rositasari, R. 1997. Habitat Mikro dan Makro pada Foraminifera. Oseana XXII(4): 31-42.

Rositasari, R. \& Sudibjo, B.S. 2008. Post Mortem Foraminifera Distribution in Aceh Water post Tsunami. Journal of Coastal Development XII (1):30-40

Suwarti, T. \& Wikarno, R. 1992. Peta Geologi Lembar Kudus Skala 1:100.000, Jawa Tengah. Pusat Penelitian dan Pengembangan Geologi: Bandung

Van Marle, L.J., 1989. Benthic Foraminifera From Banda Arc Region, Indonesia, and Their Paleobathymetric Significance For Geologic Interpretations of The Late Cenozoic Sedimenary Record. Free University Press, Amsterdam; 271 hal. 